\title{
Transition to Persistent Orofacial Pain after Nerve Injury Involves Supraspinal Serotonin Mechanisms
}

\author{
Masamichi Okubo, ${ }^{1 \star}$ Alberto Castro, ${ }^{2 \star}$ Wei Guo, ${ }^{1}$ Shiping Zou, ${ }^{1}$ Ke Ren, ${ }^{1}$ Feng Wei, ${ }^{1}$ Asaf Keller, ${ }^{2}$ and Ronald Dubner ${ }^{1}$ \\ ${ }^{1}$ Department of Neural and Pain Sciences, Dental School and ${ }^{2}$ Department of Anatomy and Neurobiology, Medical School; Program in Neuroscience, \\ University of Maryland, Baltimore, Maryland 21201
}

\begin{abstract}
The orofacial region is a major focus of chronic neuropathic pain conditions characterized by primary hyperalgesia at the site of injury and secondary hyperalgesia outside the injured zone. We have used a rat model of injury to the maxillary branch (V2) of the trigeminal nerve to produce constant and long-lasting primary hyperalgesia in the V2 territory and secondary hyperalgesia in territories innervated by the mandibular branch (V3). Our findings indicate that the induction of primary and secondary hyperalgesia depended on peripheral input from the injured nerve. In contrast, the maintenance of secondary hyperalgesia depended on central mechanisms. The centralization of the secondary hyperalgesia involved descending 5-HT drive from the rostral ventromedial medulla and the contribution of 5-HT3 receptors in the trigeminal nucleus caudalis $(\mathrm{Vc})$, the homolog of the spinal dorsal horn. Electrophysiological studies further indicate that after nerve injury spontaneous responses and enhanced poststimulus discharges in Vc nociresponsive neurons were time-dependent on descending 5-HT drive and peripheral input. The induction phase of secondary hyperalgesia involved central sensitization mechanisms in Vc neurons that were dependent on peripheral input, whereas the maintenance phase of secondary hyperalgesia involved central sensitization in Vc neurons conducted by a delayed descending 5-HT drive and a persistence of peripheral inputs. Our results are the first to show that the maintenance of secondary hyperalgesia and underlying central sensitization associated with persistent pain depend on a transition to supraspinal mechanisms involving the serotonin system in rostral ventromedial medulla-dorsal horn circuits.
\end{abstract}

\section{Introduction}

The orofacial region is a major focus of persistent or chronic neuropathic pain conditions. Common characteristics of these conditions are primary mechanical hyperalgesia or hypersensitivity at the site of injury and secondary mechanical hyperalgesia (Shibuta et al., 2012) or extra-territorial hypersensitivity (Tal and Bennett, 1994; Tsuboi et al., 2004) outside the injured zone. Both peripheral input and central mechanisms underlie the development of hyperalgesia after nerve injury. It is now commonly proposed (Basbaum et al., 2009; Staud et al., 2010; Woolf, 2011) that the induction of hyperalgesia is dependent on increased sensitivity of peripheral nociceptors, ion channels, and chemical mediators whose activation leads to neuronal hyperactivity referred to as central sensitization at the level of the spinal dorsal horn. It is assumed that these peripheral mechanisms are also responsible for the maintenance of the hyperalgesia. However, it is not clear whether peripheral drive is sufficient for the maintenance of long-term primary hyperalgesia after injury. Whether these same mechanisms apply to the maintenance of secondary hyperalgesia

\footnotetext{
Received July 16, 2012; revised Jan. 22, 2013; accepted Jan. 29, 2013.

Author contributions: K.R., F.W., A.K., and R.D. designed research; M.O., A.C., W.G., and S.Z. performed research;

M.O. and A.C. analyzed data; F.W., A.K., and R.D. wrote the paper.

This work was supported by the National Institutes of Health Grant DE021804.

The authors declare no competing financial interests.

${ }^{*} M$.O. and A.C. contributed equally to this work.

Correspondence should be addressed to Dr. Ronald Dubner, Department of Neural and Pain Sciences, University

of Maryland, 650 W. Baltimore Street, Baltimore, MD 21201-1586. E-mail: rdubner@umaryland.edu.

DOI:10.1523/JNEUROSCI.3390-12.2013

Copyright $\odot 2013$ the authors $\quad 0270-6474 / 13 / 335152-10 \$ 15.00 / 0$
}

also requires further study. A study of the long-term persistence of secondary hyperalgesia may also help in understanding the central mechanisms responsible for the transition of acute pain to chronic pain. There is increasing evidence that the transition to chronic pain is dependent on plasticity in supraspinal structures (Ren and Dubner, 2008).

The primary aims of this study are to examine the mechanisms that underlie the maintenance of secondary hyperalgesia after nerve injury and to determine whether central changes may account for the transition of acute pain to chronic, long-lasting pain. We have adapted a neuropathic pain model of chronic constriction injury (CCI) of the trigeminal infraorbital nerve (ION) that exhibits mechanical hyperalgesia and allodynia that is constant and persists for months (Wei et al., 2008). The model exhibits primary hyperalgesia in the trigeminal maxillary dermatome (V2) innervated by the ION and secondary hyperalgesia outside the zone of injury in the mandibular territory (V3). The secondary hyperalgesia is initially completely dependent on neural activity from the ION but later can persist despite a reduction in peripheral input, suggesting a centralization of the necessary pain signals associated with chronicity. Using extracellular single-unit recordings in the trigeminal subnucleus caudalis (Vc), the trigeminal homolog of the spinal dorsal horn, we found, parallel to our behavioral findings, time-dependent changes in the responses of nociresponsive neurons at this central site after injury.

The rostral ventromedial medulla (RVM) in the brainstem activates a descending neuronal pathway to the medullary and spinal dorsal horns leading to enhanced excitability and behav- 
ioral hyperalgesia after injury (Porreca et al., 2002; Ren and Dubner, 2008). These descending projections are in part serotonergic (Green et al., 2000; Zeitz et al., 2002), and the descending 5-HT system has a pronociceptive function after inflammation (Suzuki et al., 2002) and nerve injury (Wei et al., 2010). We found that descending 5-HT from the RVM and 5-HT3 receptors in Vc are involved in the central mechanisms underlying the enhanced neuronal excitability in Vc nociceptive neurons and the behavioral long-term maintenance of secondary hyperalgesia. Our results are the first to show that the continued maintenance of central sensitization in the Vc and secondary mechanical hyperalgesia are dependent on a transition, in part, to supraspinal mechanisms involving the serotonin system in RVM-dorsal horn circuits.

\section{Materials and Methods}

Adult male Sprague Dawley rats weighing 175-350 g (Harlan) were used in all experiments. Rats were on a $12 \mathrm{~h}$ light/dark cycle and received food and water ad libitum. The experiments were approved by the Institutional Animal Care and Use Committee of the University of Maryland Dental School.

Surgical preparation. A model of trigeminal neuropathic pain was prepared by CCI to the unilateral ION, described previously (Wei et al., 2008). Animals were anesthetized with pentobarbital sodium $(50 \mathrm{mg} / \mathrm{kg}$, i.p.), and intraoral surgery was performed under an operation microscope. An 8- to 10-mm-long incision was made along the gingivobuccal margin in the buccal mucosa, beginning immediately next to the first molar. The ION was freed from surrounding connective tissue by a glass rod and clearly visualized using a surgical microscope. At 3-4 $\mathrm{mm}$ from the nerve where it emerges from the infraorbital foramen, the ION was loosely tied with two chromic gut (4.0) ligatures, $2 \mathrm{~mm}$ apart. This caused minor constriction of the ION, such that the superficial vasculature was minimally disturbed. The wound was checked for hemostasis, and the incision was closed using three 4.0 silk sutures. Sham-operated rats received only a unilateral nerve exposure without ligature. All surgical procedures were performed aseptically. In some cases, a long lasting anesthetic agent $0.25-0.5 \%$ bupivacaine was injected at the incision sites 3 times per day for 1-3 d after CCI or sham surgery to block local nociceptive inputs induced by acute tissue injury. Changes in gross behavior and body weight gain in CCI and sham rats were monitored throughout the study and were not significantly different compared with those in naive rats.

Local anesthetic block of the infraorbital nerve. To more effectively block the input of neuronal activity from the infraorbital nerve, a long-lasting nerve block mixture (NB) consisting of bupivacaine $(15 \mathrm{mg} / \mathrm{ml})+$ tetrodotoxin $(24 \mu \mathrm{l} / \mathrm{ml})+$ norepinephrine $(30 \mu \mathrm{g} / \mathrm{ml})$ was used (Berde et al., 2011). Rats with CCI-ION or sham surgery were anesthetized with $2-3 \%$ isoflurane in a gas mixture of $30 \% \mathrm{O}_{2}$ balanced with nitrogen, and the NB mixture was injected into the space around the infraorbital nerve.

Electrophysiological experiments. Rats were deeply anesthetized with urethane $(1.2 \mathrm{~g} / \mathrm{kg}$, i.p.). A jugular vein catheter was inserted for delivery of anesthetic supplements, and a tracheal cannula was inserted for artificial respiration under pancuronium paralysis. Body temperature was adjusted with a thermoregulated blanket; heart rate, $\mathrm{CO}_{2}$ levels, and reflexes were continually monitored.

For Vc extracellular recordings, a laminectomy was performed, including the axis and a portion of the occipital bone. Trigeminal ganglion recordings were performed through a craniotomy in the parietal bone. Single-unit, extracellular recordings were made with $10 \mathrm{M} \Omega$ tungsten electrodes. Data were recorded through an $\mathrm{AD}$ Instruments $\mathrm{AD}$ converter and analyzed using LabChart 7 software (AD Instruments). Receptive fields (RFs) were defined as the skin area from which stimulation, using von Frey filaments, elicits a unit discharge. The skin area was carefully marked with permanent marker and the marked area transferred to paper $\left(75 \mathrm{~g} / \mathrm{m}^{2}\right)$. The paper was weighed and values expressed as arbitrary units. Mechanical stimulation of the RF was performed applying pressure through a calibrated forceps coupled to a transducer (IITC Life
Science), and pressure curves were recorded in parallel with electrophysiological recordings. Thermal stimulation was delivered through a laser heat pulse (7 W $200 \mathrm{~ms}$, wavelength $810 \mathrm{~nm}$; AMD Lasers). This resulted in temperature increases from a baseline value of $32^{\circ} \mathrm{C}$ to $47^{\circ} \mathrm{C}$, considered in the noxious range (Urch and Dickenson, 2003). At the end of the experiment, rats were perfused transcardially with aldehydes for histology to identify recording sites.

Intra-RVM and Vc microinjections. Rats were anesthetized with 2-3\% isoflurane in a gas mixture of $30 \% \mathrm{O}_{2}$ balanced with nitrogen and placed in a Kopf stereotaxic instrument (Kopf Instruments). After infiltration of lidocaine $(2 \%)$ into the skin, a midline opening was made in the skull with a dental drill to insert a microinjection needle into the target site. The RVM consists of the midline nucleus raphe magnus and the adjacent gigantocellular reticular nucleus $\alpha$ part. The coordinates for the RVM and Vc were as follows: RVM, $10.5 \mathrm{~mm}$ caudal to bregma, midline, and $9.0 \mathrm{~mm}$ ventral to the surface of the cerebellum (Wei et al., 2010); Vc, 11 $\mathrm{mm}$ bregma, $2.6 \mathrm{~mm}$ lateral to midline, and $6.4 \mathrm{~mm}$ deep from the dura (Viggiano et al., 2005). To avoid penetration of the transverse sinus, the incisor bar was set at $4.7 \mathrm{~mm}$ below the horizontal plane passing through the interaural line. Animals were subsequently maintained at $\sim 1 \%$ isoflurane. Microinjections were performed by delivering drug solutions slowly over a $10 \mathrm{~min}$ period using a $0.5 \mu \mathrm{l}$ Hamilton syringe with a 32-gauge needle. We used drugs as follows: $2 \%$ lidocaine, $0.5 \mu \mathrm{l}$ and Y25130 hydrochloride, [N-(1-azabicyclo[2.2.2] oct-3-yl)-6-chloro-4methyl-3-oxo-3,4-dihydro-2 $\mathrm{H}$-1,4-benzoxazine-8-carboxamide hydrochloride] (130 pmol/0.5 $\mu \mathrm{l}$; Tocris) diluted in saline. As described previously for intra-RVM gene transfer (Wei et al., 2008), sure silencing shRNA plasmids for rat tryptophan hydroxylase-2 (Tph-2) were used to design the enclosed shRNA (Tph-2: TCAACATGCTCCATATTGAAT) or scrambled control (negative control Tph-2: ggaatctcattcgatgcatac) and contained the $g f p$ gene (SuperArray). Each vector $(0.5 \mu \mathrm{g} / 0.5 \mu \mathrm{l})$ was injected into the RVM. The injection needle was left in place for at least 15 min before being slowly withdrawn. A pair of Teflon-coated silverpositive and -negative electrodes were placed around the microinjection sites rostrocaudally for electroporation. For transfer of negatively charged plasmid into RVM neurons, seven square wave electric pulses ( 50 ms, 40 V, 1 Hz; model 2100; A-M Systems) were delivered (Wei et., 2008). The wound was closed and animals returned to their cages after they recovered from anesthesia. In some experiments, control or Tph-2 shRNA plasmids were injected to the RVM and then followed by placing electrodes without electroporation.

Behavior testing. A series of calibrated von Frey filaments with bending forces ranging from $9 \mathrm{mg}$ to $118 \mathrm{~g}$ were applied to the orofacial skin. The orofacial regions are innervated by three branches of the trigeminal nerve with clear dermatomal distribution for the ophthalmic (V1), maxillary (V2), and mandibular (V3) divisions. For testing primary hyperalgesia, von Frey filaments were applied to the cutaneous site innervated by the ION, a branch of V2. For assessing secondary hyperalgesia, the filaments were applied to the mandibular (V3) territory posterior-inferior to the whisker pad or to the contralateral V2 area. An active withdrawal of the head from the probing filament was defined as a response. Each von Frey filament was applied 5 times at intervals of a few seconds. The percentage response frequency (number of responses/number of stimuli $\times 100 \%$ ) to a range of von Frey filament forces was determined. After a nonlinear regression analysis, the $\mathrm{EF}_{50}$ value, defined as the von Frey filament force (g) that produces a $50 \%$ response frequency, was derived from the stimulus-response curve. We used the $\mathrm{EF}_{50}$ value as a measure of mechanical sensitivity. A leftward shift of the stimulus-response curve, resulting in a reduction of $\mathrm{EF}_{50}$, occurred after injury. This shift of the curve suggested the presence of mechanical hyperalgesia and allodynia because there was an increase in response to suprathreshold stimuli and a decreased response threshold for nocifensive behavior.

Histological reconstruction. The location of microinjection sites in the RVM were determined by visual inspection of tissue sections. Rats with misplaced microinjection sites were excluded from the data analysis.

Statistics. Data are expressed as mean \pm SEM and displayed in figures as box plots of interquartile ranges and medians. Differences in values over time of each group were tested using one-way ANOVA, followed by individual post hoc comparisons (Fisher's exact test) or pairwise compar- 
isons ( $t$ test) to assess differences between naive versus each time point of the groups. In the electrophysiology experiments, statistical distribution was assessed using the Shapiro-Wilk test (Shapiro and Wilk, 1965) for normality. Nonparametric population distribution analysis to assess statistical differences was conducted using Kruskal-Wallis test, Mann-Whitney test, or Kolmogorov-Smirnov test, as appropriate. A difference was accepted as significant if $p<0.05$.

\section{Results}

The time course of induction and maintenance of secondary mechanical hyperalgesia after trigeminal nerve injury

We previously showed the presence of long-lasting mechanical hyperalgesia in $\mathrm{V} 2$, the area innervated by the injured nerve (Wei et al., 2008). Here we further examined the time course of the secondary hyperalgesia in V3 using von Frey filaments in addition to the primary hyperalgesia in V2. Mechanical hyperalgesia and allodynia were measured as reductions in $\mathrm{EF}_{50}$ values compared with baseline. We previously showed that the surgeryinduced local tissue injury and inflammation evoked the early hypersensitivity to mechanical stimulation because local tissue anesthesia with bupivacaine completely blocked the onset of the mechanical hyperalgesia in the sham-treated group at 1-3 d (Wei et al., 2008). In this study, we further found that local tissue anesthesia with bupivacaine significantly delayed the development of behavioral hypersensitivity after CCI (Fig. 1A), suggesting that the early onset of primary hyperalgesia at $1-3 \mathrm{~d}$ after CCIION is predominately induced by local tissue injury and not nerve injury after surgery. Therefore, we defined 3-5 $\mathrm{d}$ as the early time period or induction of peak neuropathic hyperalgesia. Both primary and secondary hyperalgesia in $\mathrm{V} 2$ and $\mathrm{V} 3$, respectively, were constant over time and persisted for at least $25 \mathrm{~d}$ (Fig. 1B). In view of the constant hyperalgesia over time, we chose $14 \mathrm{~d}$ as the later time period or the maintenance period of neuropathic hyperalgesia in most experiments. We suspect that other experimental peripheral nerve injury models (Kim and Chung, 1992) exhibiting hyperalgesia also include both inflammatory and delayed neuropathic components. The delay of the nerve injury response is consistent with other findings (Sun et al., 2005; Devor, 2009).

To examine the effect of peripheral input from the injury nerve on primary and secondary hyperalgesia, a mixture of bupivacaine, TTX, and epinephrine (Berde et al., 2011) was repeatedly injected via an intraoral approach into the infraorbital
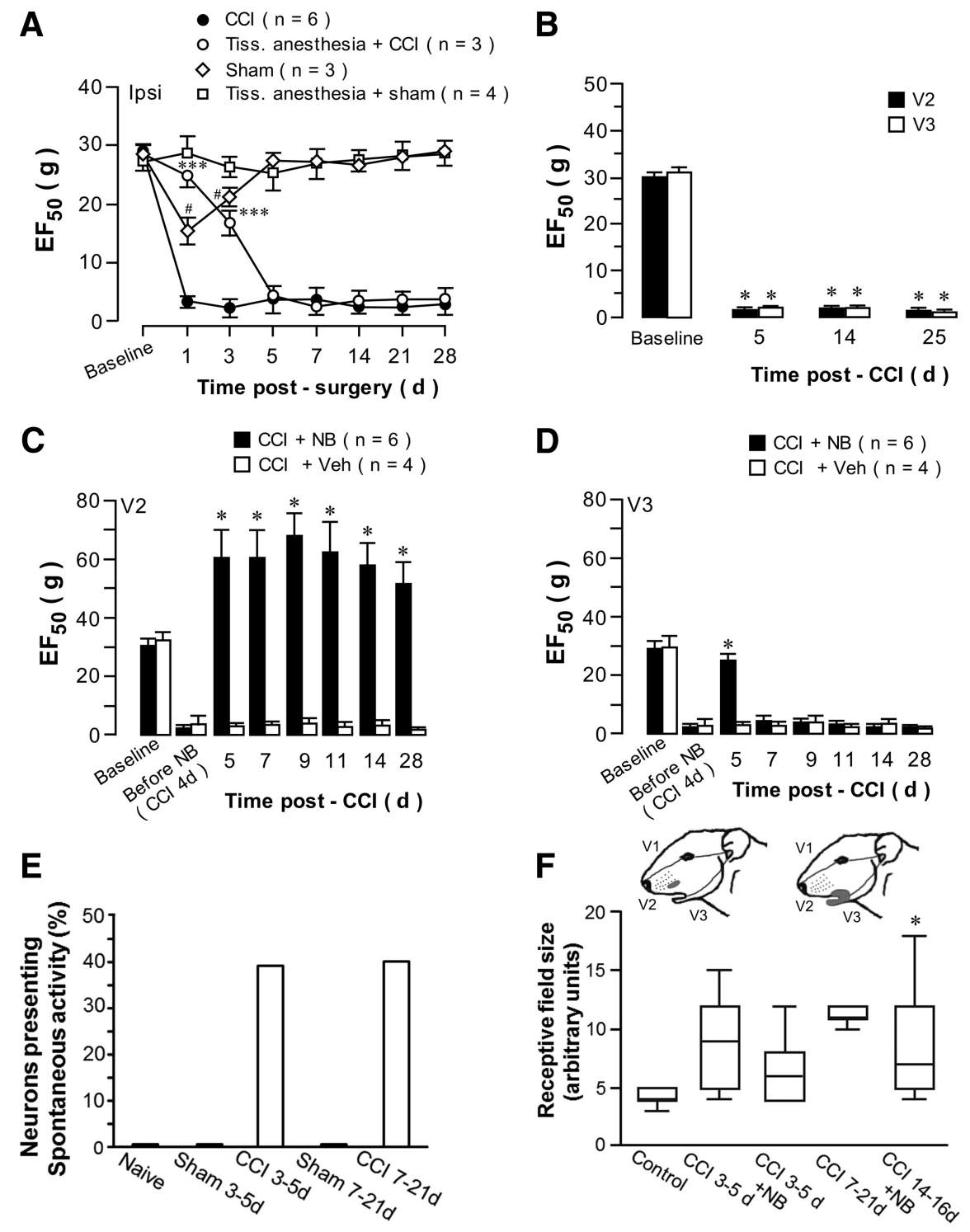

Figure 1. The time course of mechanical primary and secondary hyperalgesia and the changes in the RFs of Vc nociceptive neurons after $\mathrm{Cl}-\mathrm{ION}$. $A$, In ipsilateral V2 skin, $\mathrm{CCl}-\mathrm{ION}$ induced long-lasting primary hyperalgesia and allodynia as shown by reduced $\mathrm{EF}_{50}$ to mechanical stimuli; a transient hyperalgesia occurred 1-3 $\mathrm{d}$ after sham surgery. Repeated injections of bupivacaine into the injured tissues surrounding the ION delayed onset of primary hyperalgesia after $\mathrm{CCl}$ or completely blocked the transient hypersensitivity at $1-3 \mathrm{~d}$ after sham surgery. These data suggest that $\mathrm{CCl}-\mathrm{ION}$ resulted in a long-lasting and constant hyperalgesia beginning at $3-5 d$, and the hyperalgesia before $5 \mathrm{~d}$ was a result of tissue injury or inflammation from the surgical procedure. ${ }^{* *} p<0.001$, $\mathrm{Cl}+$ tissue anesthesia vs $\mathrm{CCl}$ alone. ${ }^{\#} p<0.05$, sham + tissue anesthesia vs sham alone. $\boldsymbol{B}$, Similar extent of primary and secondary hyperalgesia induced by $\mathrm{CCl}-10 \mathrm{~N}$ in V2 and V3 at 5, 15, and $25 \mathrm{~d}$ after $\mathrm{CCl}$. The number of rats in each group: baseline $(n=90), 5 \mathrm{~d}(n=37), 14 \mathrm{~d}(n=43)$, and $25 \mathrm{~d}(n=$ 25). ${ }^{*} p<0.05$ vs baseline. $C, D$, The functional block of the injured nerve (NB) by repeated injection of the local anesthetic mixture every day produced long-lasting local anesthetic block of the ION at $5-28 \mathrm{~d}$ after $\mathrm{CCI}-\mathrm{ION}$. The NB mixture $(50 \mu \mathrm{l})$ was given 2 times at a $12 \mathrm{~h}$ interval, and the behavioral testing in $\mathrm{V} 2$ and $\mathrm{V} 3$ was performed $6 \mathrm{~h}$ after the last injection. When administered $5 \mathrm{~d}$ after $\mathrm{CCl}$, both primary (V2) and secondary (V3) hyperalgesia were blocked by the local anesthetic mixture, whereas administration at $7-28 \mathrm{~d}$ after $\mathrm{CCl}$ only blocked primary hyperalgesia. ${ }^{*} p<0.05$, local anesthesia versus vehicle treatment. $\boldsymbol{E}$, Spontaneous activity of WDR neurons in the ipsilateral Vc. None of the neurons from control animals (naive $=7$ cells; sham at 3-5 d postsurgery $=6$; and sham at $7-21 \mathrm{~d}$ after sham surgery $=5$ ) exhibited spontaneous activity. In contrast, $39 \%$ ( 10 of 26 ) of $\mathrm{V}$ c neurons recorded at $3-5 \mathrm{~d}$ after $\mathrm{CCI}-\mathrm{ION}$ and $40 \%$ ( 10 of 25 ) neurons at $7-21$ after $\mathrm{CCl}$ exhibited spontaneous responses. $\boldsymbol{F}$, Expansion in trigeminal RFs of $\mathrm{V}$ c nociceptive neurons after $\mathrm{CCl}-\mathrm{ION}$ and effect of NB on RFs. Box plots (showing the lower, median, and upper quartiles) and whisker plots (representing data within 1.5 of the distal quartile ends) depict RF size, expressed in arbitrary units, of neurons from control (naive and sham, $n=16$ ), $\mathrm{Cl}$ $3-5 \mathrm{~d}(n=11), \mathrm{CCl} 3-5 \mathrm{~d}$ plus NB $(n=28), \mathrm{CCI} 7-21 \mathrm{~d}(n=14)$, and $\mathrm{CCl} 14-16 \mathrm{~d}$ plus NB rats $(n=12)$. RF sizes at $3-5$ $\mathrm{d}$ and later time points after $\mathrm{CCl}-\mathrm{ION}$ are significantly increased compared with that in the control groups $(p<0.001)$. NB resulted in a significant reduction in enlarged RF size induced by $\mathrm{CCl}$ at $14-16 \mathrm{~d}$ after $\mathrm{CCl}(p<0.05)$ but not at $3-5 \mathrm{~d}$ after CCI-ION ( $p=0.24)$. Figurines represent RFs (shaded in gray) from the control group (left) and the $3-5 \mathrm{~d}$ CCI-ION group (right). 
fissure of the rat to produce direct long-lasting block of the injured ION. The mixture for NB was given 2 times at a $12 \mathrm{~h}$ interval, and the behavioral testing in V2 and V3 was performed $6 \mathrm{~h}$ after the last injection. The time course of the effects of NB was examined at time periods from 5 to $28 \mathrm{~d}$ in V2 and V3. The NB of the ION blocked behavioral responses to mechanical stimulation at all time points compared with vehicle injection (Fig. $1 C$ ), but its ability to produce complete anesthesia of the ION precludes determining the NB effect on primary afferent discharge from the injured nerve. However, secondary hyperalgesia in ipsilateral V3 was blocked at $5 \mathrm{~d}$ after CCI-ION but persisted at all later time points (Fig. 1D). In some cases, secondary hyperalgesia was found in the contralateral V2 and was only blocked by the NB at the early time points (data not shown). These results suggest that at earlier time points after injury $(4-5 \mathrm{~d})$, secondary hyperalgesia is completely dependent upon peripheral input from the injured nerve but that the maintenance of secondary hyperalgesia at later time points may be dependent also upon a transition to central mechanisms. We then searched for neuronal changes in excitability in the $\mathrm{Vc}$ in the brainstem for evidence of central changes associated with secondary hyperalgesia.

\section{Response properties of nociresponsive neurons in $\mathrm{Vc}$ and trigeminal ganglion (TG) after CCI-ION}

Using single-unit extracellular recordings in vivo, we examined the time course of changes in the excitability of Vc nociceptive neurons. We compared spontaneous firing and evoked responses of wide dynamic range (WDR) neurons from CCI-ION $(n=22$ rats) and sham-operated rats $(n=20)$. We focused on WDR neurons in laminae IV-V of Vc because in the spinal dorsal horn such neurons appear to mediate central changes associated with the development of spontaneous and evoked repetitive plateau responses that exhibit activity-dependent plasticity (Morisset and Nagy, 1998; Derjean et al., 2003). WDR neurons were identified by their responses to both low threshold mechanical stimuli and to noxious mechanical stimuli, and their enhanced responses to increases in stimulus intensity in the noxious range (Urch and Dickenson, 2003; Fossat et al., 2007). As previously reported (Rygh et al., 1999; Svendsen et al., 1999; Urch and Dickenson, 2003), none of the neurons from both naive and sham animals ( $n=18$ neurons) exhibited spontaneous activity (Fig. $1 E$ ). In contrast, $39 \%$ (20 of 51) of the neurons recorded from CCI-ION animals exhibited spontaneous action potentials (Fig. 1E), at rates ranging from 4 to $40 \mathrm{~Hz}$ (median, $10 \mathrm{~Hz} ; 15 \pm 11 \mathrm{~Hz}$ ). The abnormal spontaneous activity appeared in Vc neurons as early as $3 \mathrm{~d}$ after CCI, and also existed at least at $21 \mathrm{~d}$ after CC-ION, the latest time point tested. There were no significant differences in the patterns of spontaneous activity or the percentage of neurons exhibiting spontaneous activity between the $3-5 \mathrm{~d}$ post-CCI and the 7-21 d post-CCI groups (Fig. $1 E$ ). Changes in excitability of $\mathrm{Vc}$ neurons contralateral to the ligated ION appeared $7 \mathrm{~d}$ or later after CCI-ION in some animals. In $7 \mathrm{Vc}$ neurons recorded from the contralateral side of the face, spontaneous activity was present, and this spontaneous activity occurred exclusively in neurons from animals that exhibited significant hyperalgesia $(\geq 30 \%$ decrease in mechanical thresholds).

In control (naive and sham) rats, WDR neurons responded to tactile stimulation of a small region on the face, restricted to only one of the three dermatomal divisions of the trigeminal nerve (V1, V2, or V3; Fig. 1F). We defined the size of these RFs as the total area from which responses could be evoked, expressed as arbitrary units (see Materials and Methods). In Vc neurons from control rats, the mean (and SEM) RF size was $4.5 \pm 1.1$ (median,
4). Neurons recorded at all time points after CCI exhibited an increase in RF size that was statistically significant $(p<0.001)$. Neurons recorded at 3-5 d after CCI responded to stimulation of significantly larger areas, often including both the V2 and the adjacent V3 territory. The RFs of neurons in the $7-21 \mathrm{~d}$ post-CCI group were significantly larger than those in the $3-5 \mathrm{~d}$ post-CCI group $(p<0.01)$ and included more distal zones of V3, including regions surrounding the temporomandibular joint. After $\mathrm{NB}$, the RFs of neurons in the 3-5 d post-CCI group exhibited a trend toward a decrease in size $(p=0.24$; Fig. $1 F)$. In contrast, the RFs of the neurons in the late time group exhibited a significant decrease in size after nerve injury $(p<0.05$; Fig. $1 F)$. Representative RFs for the control group (left figurine) and the 3-5 d CCI-ION group (right figurine) are shown in Figure $1 F$.

The secondary hyperalgesia in $\mathrm{V} 3$, which is resistant to local anesthetic block beginning $7 \mathrm{~d}$ after CCI-ION, may in part result from peripheral sensitization of noninjured afferents in V3, similar to effects that have been shown at spinal levels in L4 neurons after injury to L5 afferents (Ringkamp and Meyer, 2005; Shim et al., 2007). In the TG, gap junctions in satellite cells contribute to neuron-satellite signaling and may result in spread of neural activation to V3 cells that do not ordinarily receive input from the injured site (Durham and Garrett, 2010). An increase in the apparent size RFs may also reflect ectopic discharges from primary afferents in V3, resulting from ligation of V2 (Wall and Gutnick, 1974). In addition to contributing to central sensitization, these ectopic discharges may account partially for both the enhanced spontaneous activity in Vc neurons after CCI-ION and for the apparent expansion of their RFs. To test this hypothesis we obtained single-unit recordings from neurons in the ipsilateral TG (Fig. 2). As previously reported (Jones et al., 2004a, 2004b), TG neurons $(n=13)$ recorded from naive or sham rats had no spontaneous activity. In contrast, $44 \%$ of TG neurons ( 8 of 18 ) recorded from the $3-5 \mathrm{~d}$ post-CCI-ION group and $28 \%$ of neurons $(5-18)$ in the $7-21$ post-CCI group fired spontaneously, exhibiting irregular firing patterns, at rates ranging from 0.13 to $200 \mathrm{~Hz}(7.5 \pm 0.8 \mathrm{~Hz})$. There were no significant differences in discharge patterns and frequency of spontaneous activity between the neurons in the $3-5 \mathrm{~d}$ postCCI and the 7-21 d post-CCI groups.

Consistent with previous reports, TG neurons recorded from control rats had small, punctuate RFs. As early as $3 \mathrm{~d}$ after CCI, these neurons responded to larger trigeminal territories, which now included the skin overlapping the nerve track. These changes likely reflect CCI-induced ectopic mechano-sensitive generators, which have been described previously in various neuropathies (Chen and Devor, 1998; Devor, 2009).

Some electrophysiological findings in Vc cannot be explained by peripheral changes, and are likely to involve central neuronal plasticity. The enlargement of Vc RFs, including distal V3 territories and the contralateral face at $7 \mathrm{~d}$ and later time points after CCI-ION, cannot be readily accounted for by peripheral mechanisms alone. Similarly, the secondary hyperalgesia that is resistant to peripheral NB after $5 \mathrm{~d}$ CCI cannot be explained by peripheral mechanisms (Fig. 1). The following experiments were designed to test the hypothesis that these behavioral and electrophysiological phenomena reflect central changes in $\mathrm{Vc}$, and whether these phenomena are causally related to each other.

We compared the responses to graded mechanical stimuli of WDR neurons in Vc of sham-treated rats with those recorded from rats with CCI-ION. Figure $3 A$ shows neuronal recordings 
A
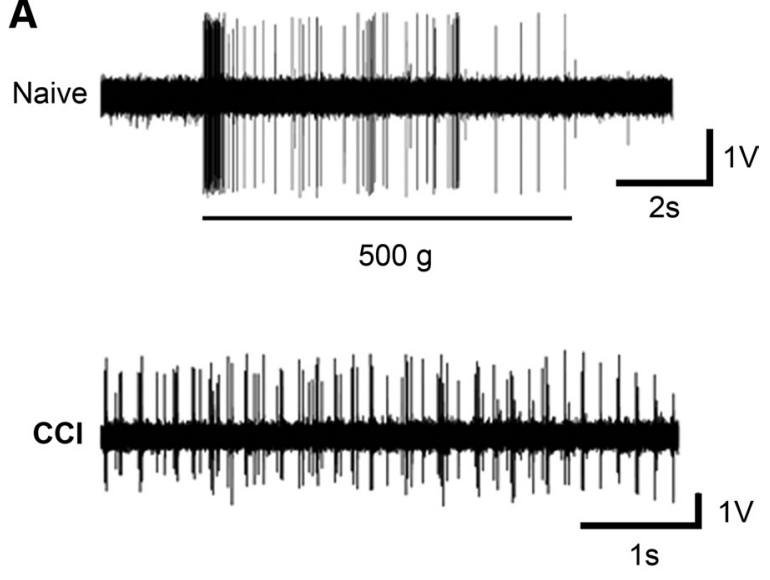

B

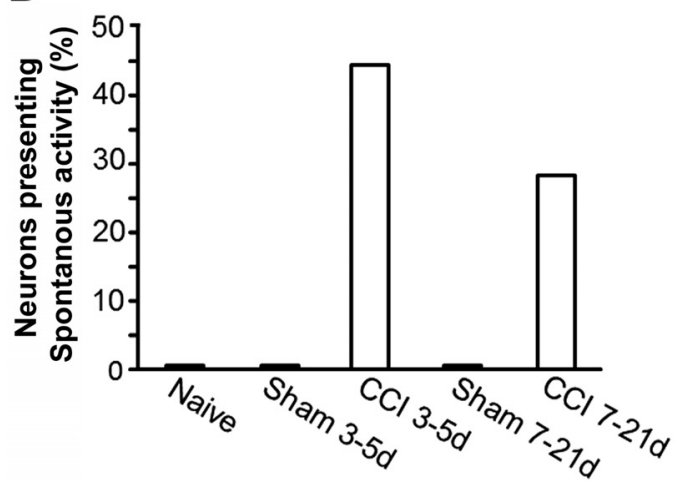

Figure 2. Response patterns of TG neurons in naive, sham, and post-CCl rats. $\boldsymbol{A}$, Top, Evoked discharge produced by a $500 \mathrm{~g}$ mechanical stimulus in a naive rat; there is absence of spontaneous activity. Bottom, Spontaneous activity in a neuron at $5 \mathrm{~d}$ after $\mathrm{CCl}$ injury. $\boldsymbol{B}$, Absence of spontaneous activity in naive $(n=7)$ and sham rats ( $3-5$ d after sham surgery, $n=3$; and 7-21 d after sham, $n=3$ ). In contrast, $44 \%$ (8 of 18) of neurons from 3 to $5 \mathrm{~d}$ post-CCl-ION rats and $28 \%$ (5 of 18 ) from 7 to $21 \mathrm{~d}$ post-CCl-ION rats exhibited spontaneous activity.

illustrating the typical patterns found in naive and CCI-ION animals at different time points. The recording from a WDR neuron in a naive rat demonstrates the absence of spontaneous activity and the response to a calibrated pinch stimulus applied to the neuron's RF. The response terminated at the end of the stimulus period. As previously reported (Martin et al., 2010), Vc neurons from CCI-ION rats exhibited prolonged poststimulus discharges that outlasted the stimulus. The frequency and duration of the poststimulus discharges at different time points after CCI-ION are quantified in Figure $3 B, C$. The poststimulus activity recorded from the 3-5 d post-CCI-ION animals had significantly longer durations (median, $175 \mathrm{~s} ; p<0.001$ ) compared with those in control rats (median, $3 \mathrm{~s}$ ). The poststimulus discharge frequency was also significantly higher in $3-5 \mathrm{~d}$ post-CCI-ION rats (median, $5.4 \mathrm{~Hz} ; p<0.001$ ) compared with control rats (median, 1.5 $\mathrm{Hz}$ ). A similar increase of the poststimulus duration (median, $76 \mathrm{~s}$ ) and frequency (median, $6 \mathrm{~Hz}$ ) in the $7-21 \mathrm{~d}$ post-CCI-ION group was found compared with the control group $(p<0.01$ and $p<0.001$, respectively; Fig. $3 B, C)$. There were no significant differences between the frequency and duration of the poststimulus discharges recorded from the 3-5 d post-CCI and the 7-21 d post-CCI groups. Poststimulus discharges were recorded from $80 \%$ of the rats with CCI-ION $(n=22)$ but only from $30 \%$ of control rats $\left(n=20 ; \chi^{2}\right.$ test $\left.p<0.01\right)$.
NB significantly decreased poststimulus frequency in both the early time points $(p<0.01)$ and later time points $(p<0.001)$ after CCI (Fig. 3B). NB significantly decreased poststimulus duration in the early time period after CCI-ION $(p<0.001)$ but not the later time points $(p=0.5)$ (Fig. $3 C$ ). These findings suggest that postdischarge frequency recorded in the induction phase and in the later maintenance phase was peripheral inputdependent. In contrast, postdischarge duration in the later maintenance phase apparently was not dependent on peripheral input.

In rats with contralateral hyperalgesia the duration of poststimulus discharge in $\mathrm{Vc}$ neurons was significantly longer $(96.6 \pm 86.0 \mathrm{~s}$, median, $52 \mathrm{~s} ; p<0.001)$ compared with that from rats with no contralateral hyperalgesia (1.6 $\pm 0.7 \mathrm{~s}$; median, $1 \mathrm{~s})$ (Fig. 3D). Similarly, Vc neurons $(n=7)$ with contralateral abnormalities (spontaneous activity and prolonged postdischarges) were recorded only from animals that exhibited contralateral hyperalgesia, which was defined as $\geq 30 \%$ decrease in withdrawal threshold compared with that in rats with no contralateral hypersensitivity $(p<0.001)$. Thus, the correlation between the induction phase of duration of postdischarges and the development of behavioral hyperalgesia is consistent with the premise that the two are causally related.

In addition to the prominent increase in poststimulus discharges, Vc neurons from CCI-ION rats had pronounced enhanced activity with repetitive mechanical stimuli. This is depicted in a representative recording in Figure $3 \mathrm{E}$. There is a gradual increase in the duration of poststimulus discharges in response to three repetitive stimuli. The incidence of neurons showing enhanced activity with repetitive stimulation was similar in CCI-ION (19 of 51; 38\%) and sham-operated rats (5 of 24; $20 \%)$. However, in neurons from CCI-ION rats, repetitive stimuli produced larger increases in the duration of responses recorded from neurons from 7 to $21 \mathrm{~d}$ post-CCI group than from 3 to $5 \mathrm{~d}$ post-CCI and sham-operated rats (Fig. $3 F$ ).

The maintenance of long-term hyperalgesia after CCI-ION is dependent upon descending inputs from the RVM to Vc

Our electrophysiology findings in Vc suggest that changes occur in neuronal activity after CCI-ION that is not dependent upon peripheral input. Therefore, peripheral changes in neural excitability may not be sufficient for the maintenance of secondary hyperalgesia. We tested the hypothesis that descending facilitatory input contributes to its maintenance because previous studies indicate that descending neuronal pathways from the RVM to the medullary and spinal dorsal horns lead to enhanced excitability and behavioral hyperalgesia after injury (Suzuki et al., 2002; Lagraize et al., 2010; Wei et al., 2010; Burgess et al., 2002).

The effect of microinjection of lidocaine $(2 \%, 0.5 \mu \mathrm{l})$ into the brainstem RVM on V2 and V3 hyperalgesia was examined at two time points ( 5 and $14 \mathrm{~d}$ ), which bridged the transition from primary afferent drive-dependent hyperalgesia to possibly centrally dependent effects (Fig. 4). Lidocaine microinjection had no effect on primary (V2) and secondary (V3) hyperalgesia when administered at $5 \mathrm{~d}$ after CCI-ION compared with a vehicle treatment. In contrast, at $14 \mathrm{~d}$ after CCI-ION, intra-RVM lidocaine attenuated both primary and secondary hyperalgesia with no effect of the vehicle RVM injection. There were no effects of lidocaine administered to sham-operated rats (data not shown). Thus, peripheral input from an injured nerve has dominant effects on primary and secondary hyperalgesia in the induction phase, but secondary hyperalgesia appears more dependent on CNS effects in the transition to persistent hyperalgesia during the later maintenance phase. 


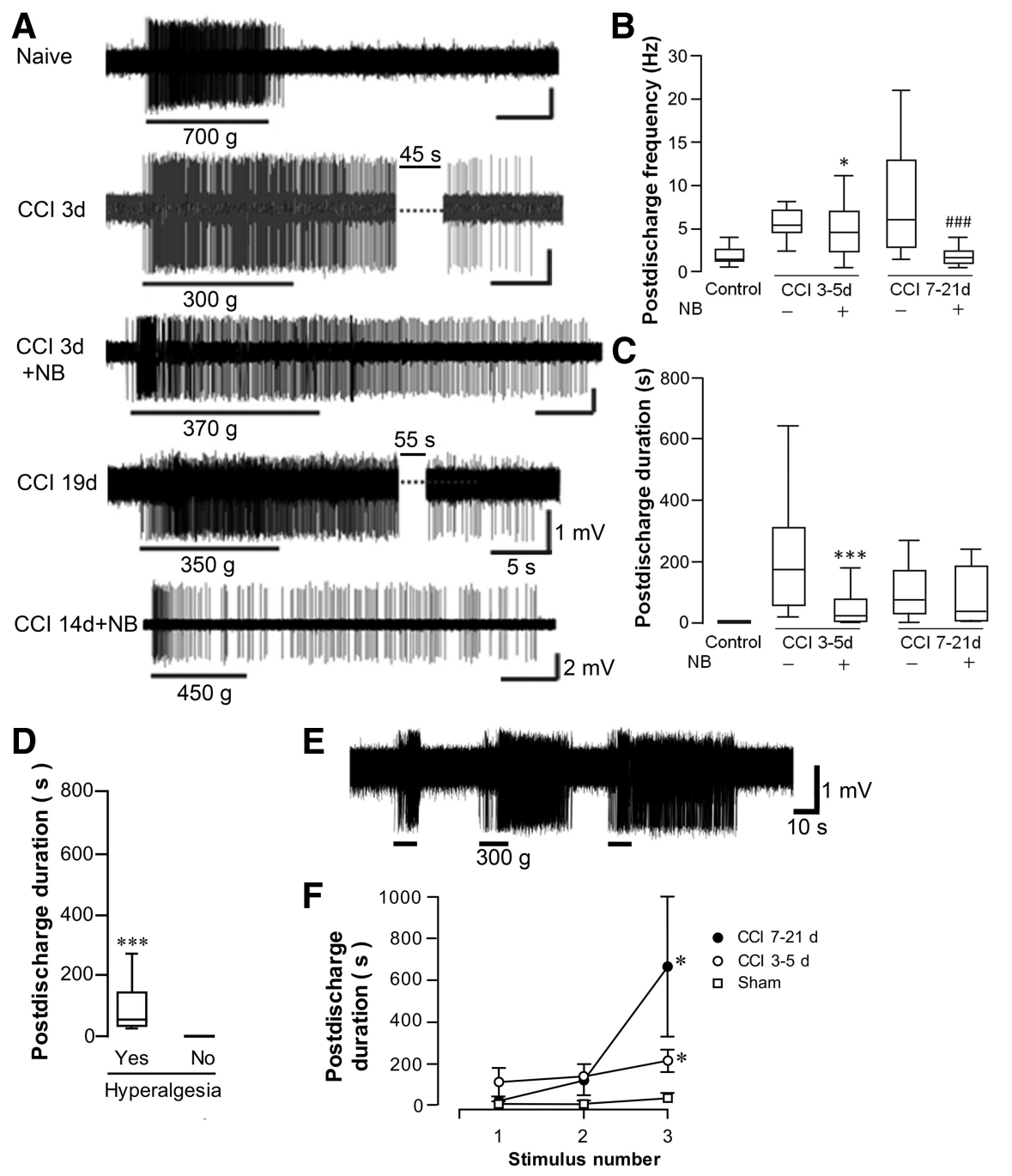

Figure 3. Enhanced poststimulus discharges of WDR neurons in the V after CCI-ION and their changes after NB. A, The typical patterns of evoked responses recorded in a naive rat and $\mathrm{CC}$-treated rats at the early and later time points with or without NB. The cuts in the traces from $\mathrm{CCl} 3$ and 19 dindicate the time periods within the traces that have been omitted. Vc neurons from $\mathrm{CCl}-\mathrm{ION}$ rats exhibited pronounced and prolonged poststimulus discharges that outlasted the stimulus. B, C, Quantified magnitude of the poststimulus discharges of $V$ c neurons. Stimulus postdischarges in the box plots represent the lower, median, and upper quartiles. An increase of postcharge frequency $(\boldsymbol{B})$ and duration $(\boldsymbol{C})$ was found at both the early and later time points after $\mathrm{C}(\mathrm{C}$. Stimulus postdischarge frequency was calculated as instantaneous frequencies of the neurons during the postdischarge time. Stimulus postdischarge duration was calculated as the time from the end of the stimulus to the last action potential. NB significantly

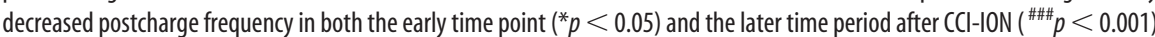
$(B)$. NB significantly decreased poststimulus duration in the early time point $\left({ }^{* *} p<0.001\right)$ but not the later time period post-CCI-ION $(p=0.5)\left(\boldsymbol{C}\right.$. D, Postdischarge duration of contralateral Vc neurons was significantly longer $\left({ }^{* * *} p<0.001\right)$ in animals with hyperalgesia contralateral to $\mathrm{CCI}-\mathrm{ION}$ compared with those with no contralateral hyperalgesia. $E$, Vc neurons after $C \mathrm{Cl}$ exhibited a progressive increase in magnitude and frequency in response to repetitive mechanical stimulation. $\boldsymbol{F}$, Group data showed that the duration of evoked responses was minimally affected by repeated stimuli in Vc neurons from sham rats $(n=8$ neurons) and the $\mathrm{CCl} 3-5 \mathrm{~d}$ group $(n=6)$, whereas in the 7-21 d post-CCI rats $(n=8)$, subsequent stimuli evoked larger responses ( ${ }^{*} p<0.05$ vs sham).

The maintenance of long-term secondary hyperalgesia after nerve injury is dependent upon an enhancement of descending facilitatory 5-HT inputs from the RVM to Vc and activation of $5-\mathrm{HT}_{3}$ receptors in the $\mathrm{Vc}$

In previous studies (e.g., Wei et al., 2010), we have determined the role of descending 5-HT from RVM neurons in nocifensive behaviors after persistent pain by selectively depleting 5-HT with regional RNA interference of $T p h-2$, the rate-limiting enzyme in the synthesis of neuronal 5-HT in the CNS. Tph-2 shRNA induced prolonged downregulation of Tph-2 in the RVM and almost complete depletion of 5-HT in the spinal and medullary dorsal horns (Wei et al., 2010; Chai et al., 2012). The treatment attenuated both tissue and nerve injury-induced hyperalgesia and allodynia. We further tested the hypothesis that the transition to the maintenance phase of nerve injuryinduced secondary hyperalgesia was dependent on an enhancement of descending 5-HT facilitatory inputs from RVM to Vc. To deplete 5-HT in RVM neurons, plasmid for Tph-2 shRNA was microinjected and transferred by electroporation in the RVM at $3 \mathrm{~d}$ before the behavior testing (Fig. 5). Tph-2 shRNA treatment in the RVM had no significant effect on primary and secondary hyperalgesia at $5 \mathrm{~d}$ after CCI-ION (Fig. 5A). However, the Tph-2 shRNA treatment attenuated both primary and secondary hyperalgesia at 14 and $28 \mathrm{~d}$ after CCI-ION (Fig. $5 B, C$ ). This treatment also completely blocked the contralateral hyperalgesia observed in some animals at $14 \mathrm{~d}$ after CCI-ION surgery, further supporting its dependence on descending facilitatory 5-HT mechanisms from the RVM (Fig. 5D).

Although 5-HT activates a number of heterogeneous receptors in the dorsal horn, an excitatory response is mediated through the ionotropic $5-\mathrm{HT}_{3}$ receptor (Suzuki et al., 2002; Lagraize et al., 2010; Wei et al., 2010). We therefore predicted that the administration of a $5-\mathrm{HT}_{3}$ receptor antagonist microinjected into the $\mathrm{Vc}$ would attenuate or completely reverse the late-phase secondary hyperalgesia. The effects of microinjection of the $5-\mathrm{HT}_{3}$ receptor antagonist, Y25130, into the Vc on the primary and secondary hyperalgesia after CCI-ION were then examined (Fig. 6). Y25130 had a minimal effect on both primary and secondary hyperalgesia at $5 \mathrm{~d}$ after CCI-ION compared with the vehicle treatment (Fig. $6 A)$. At $14 \mathrm{~d}$ after CCI-ION, Y25130 significantly attenuated both primary and secondary hyperalgesia for $6 \mathrm{~h}$ after a single Y25130 microinjection compared with the vehicle-treated group (Fig. 6B), suggesting that $5-\mathrm{HT}_{3}$ receptor activation in the Vc contributes to the maintenance of hyperexcitability in $\mathrm{Vc}$ neurons in both V2 and V3.

We next examined the combined effects of NB followed by administration of the $5-\mathrm{HT}_{3}$ receptor antagonist, Y25130, on secondary hyperalgesia in the V3 area, to determine the relative importance of peripheral input and central modulation in the late phase of hyperalgesia at $14 \mathrm{~d}$ (Fig. 6C). NB with the local anesthetic mixture had statistically a nonsignificant attenuating effect on the secondary hyperalgesia from V3. In contrast, a subsequent microinjection of Y25130 into the Vc had a significant attenuating effect of the secondary hyperalgesia, although the $\mathrm{EF}_{50}$ value did not return to the baseline level. This finding suggests that descending 5-HT facilitatory input provides a major 

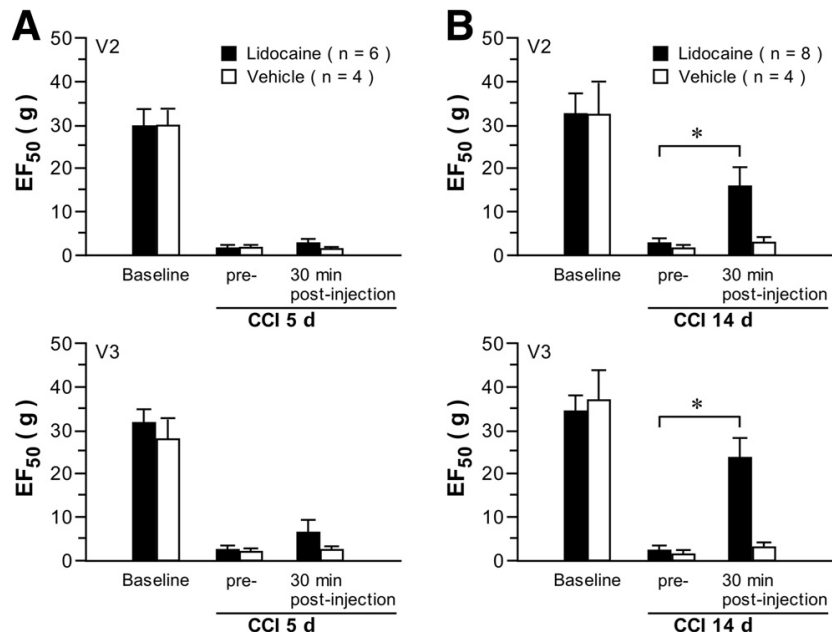

Figure 4. Effect of intra-RVM microinjection of lidocaine on the primary and secondary hyperalgesia after $C \mathrm{Cl}-\mathrm{ION}$. Microinjection of lidocaine $(2 \%, 0.5 \mu \mathrm{l})$ was done at $5 \mathrm{~d}(\boldsymbol{A})$ and $14 \mathrm{~d}$ $(B)$ after $C(\mathrm{Cl}-\mathrm{ION} A$. Lidocaine had no effect on primary and secondary hyperalgesia at $5 \mathrm{~d}$ after $\mathrm{CCl}$ compared with the vehicle-treatment group. $\boldsymbol{B}$, At $14 \mathrm{~d}$ after $\mathrm{Cl}$, lidocaine attenuated both primary and secondary hyperalgesia at $30 \mathrm{~min}$ after lidocaine treatment compared with the vehicle treatment, suggesting that secondary hyperalgesia was maintained by central mechanisms involving RVM input. ${ }^{*} p<0.05$, lidocaine vs vehicle.

contribution to the V3 hyperalgesia in the late maintenance phase.

\section{5-HT depletion attenuates Vc poststimulus neuronal activity in the CCI-ION rat}

Because Tph-2 shRNA treatment in the RVM attenuated latephase secondary hyperalgesia, we compared the Vc poststimulus neuronal activity between CCI-ION Tph-2 shRNA and control shRNA-treated rats at $14 \mathrm{~d}$ to determine whether RVM 5-HT depletion in the $\mathrm{Vc}$ altered the response properties of $\mathrm{Vc}$ neurons (Fig. 7). The depletion of RVM 5-HT had no effect on the RF size (Fig. 7A) or the level of spontaneous activity (Fig. $7 B$ ) in Vc neurons, suggesting that these phenotypes are dependent on peripheral input. In contrast, treatment with Tph-2 shRNA significantly resulted in shorter duration $(64.4 \pm 189 \mathrm{~s}$; median, $13 \mathrm{~s}$; $n=22$ neurons $)$ and frequency $(1.7 \pm 1 \mathrm{~Hz}$; median, $1.8 \mathrm{~Hz} ; n=$ 22 neurons, $p<0.001)$ in poststimulus discharges compared with those from CCI-ION animals treated with control shRNA $(188.1 \pm 189.5 \mathrm{~s}$; median, $116 \mathrm{~s} ; n=12 ; 10.6 \pm 6.5 \mathrm{~Hz}$; median, $8.1 \mathrm{~Hz}$, respectively). Thus, depletion of serotonergic inputs from RVM significantly attenuated the poststimulus neuronal activity of Vc neurons in CCI-ION animals, consistent with its effects on late-phase secondary hyperalgesia.

\section{Discussion}

We have used a model of nerve injury to produce constant and long-lasting primary and secondary hyperalgesia in the V2 and V3 territories of the trigeminal nerve. Our findings indicate that, at early time points after CCI, secondary hyperalgesia in V3 is completely dependent on input from the site of injury. However, the secondary hyperalgesia that is maintained for $7-28 \mathrm{~d}$ is primarily dependent on central mechanisms involving 5-HT drive from the RVM and activation of 5-HT3 receptors in the Vc. The relative contributions of peripheral and central mechanisms to the primary hyperalgesia over the 3-28 d period cannot be determined because of the complete block of behaviorally evoked responses in V2 after local anesthesia of injured nerve. Furthermore, there are time-dependent changes in nociresponsive
A

Tph-2 shRNA ( $n=4-7)$

$\square$ Control shRNA $(n=3-4)$
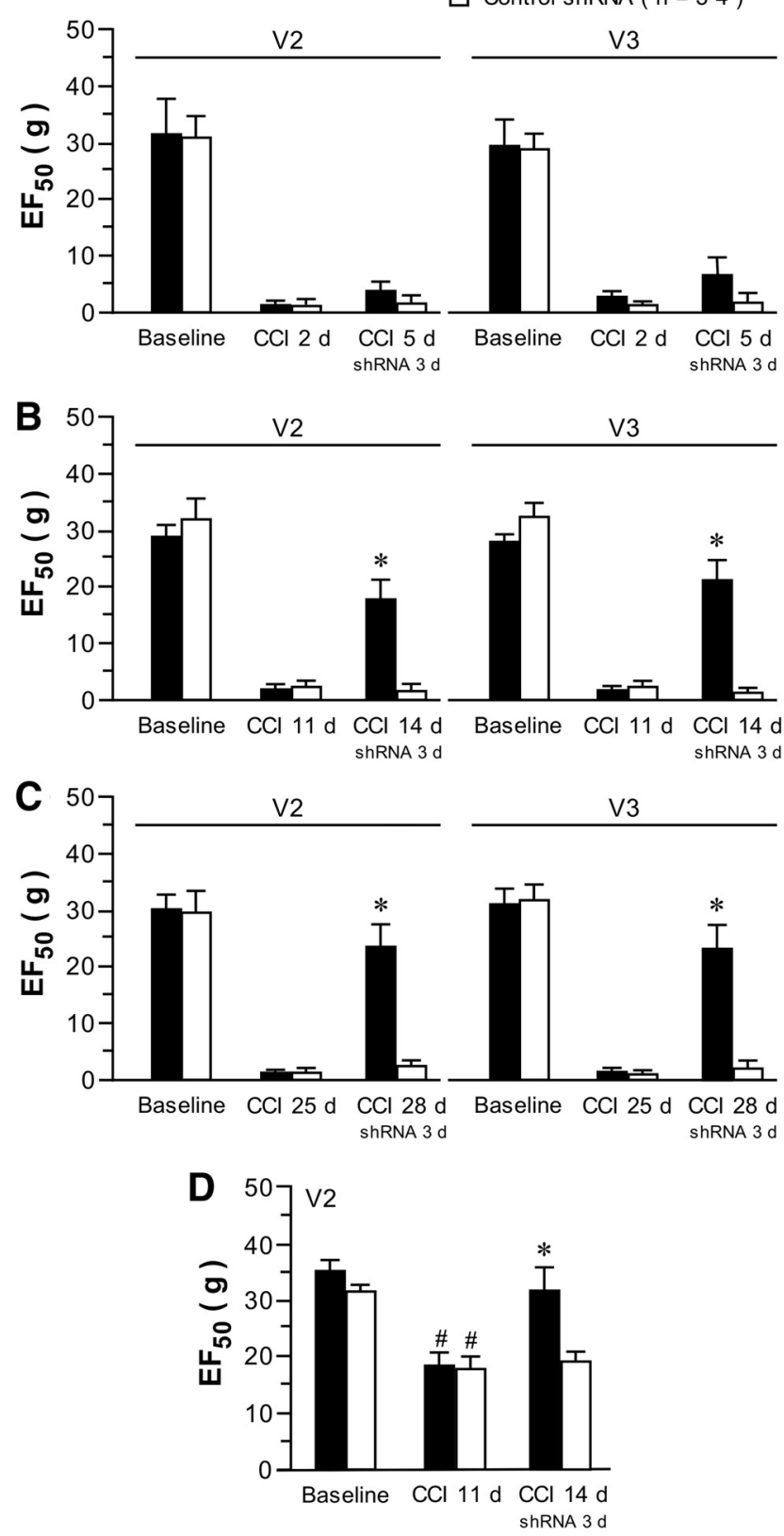

Figure 5. Contribution of descending 5-HT to the maintenance of primary and secondary hyperalgesia. $A$, Depletion of descending 5-HT with intra-RVM Tph-2 shRNA treatment had no significant effect on primary and secondary hyperalgesia at $5 \mathrm{~d}$ after $\mathrm{CCl}$. B, C, Depletion of descending 5-HT attenuated both primary and secondary hyperalgesia at 14 and $28 \mathrm{~d}$ after CCI-ION. D, Contralateral hyperalgesia in V2 observed in some rats $(n=10)$ was completely blocked by descending 5 -HT depletion. ${ }^{*} p<0.05$, Tph-2 shRNA vs control shRNA. ${ }^{\#} p<0.05$, $11 \mathrm{~d}$ after C(I-ION vs baseline.

Vc neurons, including spontaneous activity and enhanced poststimulus discharges after CCI-ION. The finding that central sensitization in the $\mathrm{Vc}$ is causally related to the maintenance of secondary hyperalgesia is supported by the fact that it is also dependent on 5-HT inputs from RVM.

Time-dependent difference in mechanisms of secondary hyperalgesia and allodynia in the rat CCI-ION model A major finding in this study is that the constant level and maintenance of secondary hyperalgesia after its initial induction at 3-5 
A

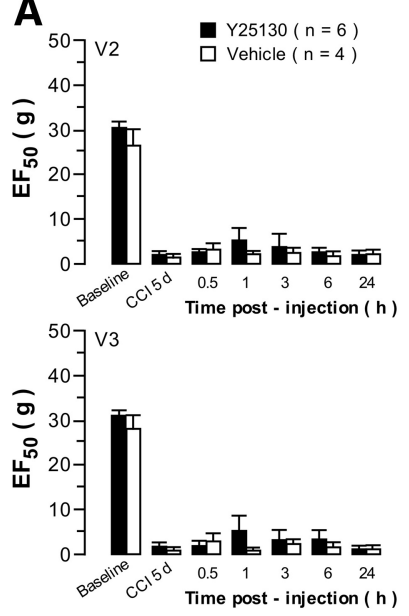

B
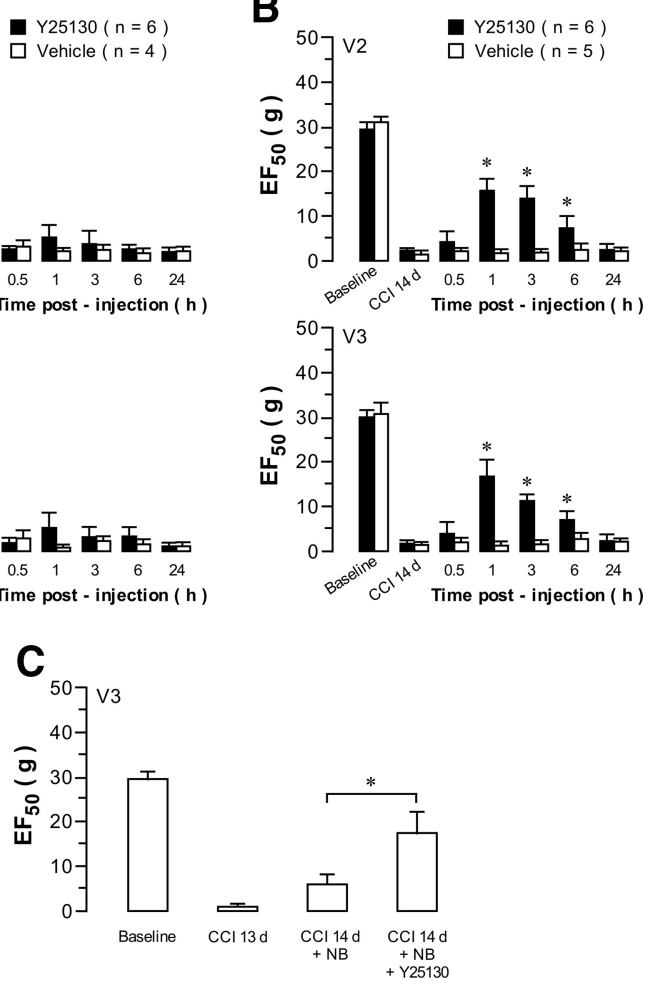

Figure 6. Effect of blockade of $5-\mathrm{HT}_{3}$ receptor function in the ipsilateral $\mathrm{Vc}$ on the primary and secondary hyperalgesia after $\mathrm{CCI}-\mathrm{ION}$. The $5-\mathrm{HT}_{3}$ receptor antagonist $\mathrm{Y} 25130$ $(130 \mathrm{pmol}, 0.5 \mu \mathrm{l})$ was injected into the $\mathrm{Vc}$ at 5 and $14 \mathrm{~d}$ after $\mathrm{CCl}$. $\boldsymbol{A}, \mathrm{Y} 25130$ had a minimal effect on both primary and secondary hyperalgesia at $5 \mathrm{~d}$ after $\mathrm{Cl}$ compared with the vehicle-treated group. $\boldsymbol{B}$, At $14 \mathrm{~d}$ after $\mathrm{CCl}, \mathrm{Y} 25130$ significantly attenuated both primary and secondary hyperalgesia at 1-6 $\mathrm{h}$ after microinjection compared with the vehicle, suggesting that $5-\mathrm{HT}_{3}$ receptor activation in $\mathrm{Vc}$ contributes to the late hyperalgesia. C, Effect of NB followed by blockade of $5-\mathrm{HT}_{3}$ receptors on secondary hyperalgesia measured in the V3 area at $14 \mathrm{~d}$ after $\mathrm{CCl}$; the local anesthetic mixture had a minor nonsignificant effect on the secondary hyperalgesia from $\mathrm{V} 3$; a subsequent microinjection of Y25130 into the Vc had a significant attenuating effect on hyperalgesia. ${ }^{*} p<0.05$; Y25130 vs vehicle. $n=5$ per group.

$\mathrm{d}$ and for at least $28 \mathrm{~d}$ involve a transition from peripheral afferent drive to central mechanisms and activation of RVM circuitry. We determined the presence of this shift using local anesthetic block of the injured ION and microinjection of the anesthetic into the RVM. The ION block terminated primary hyperalgesia in V2 over the 5-28 d time course, whereas secondary hyperalgesia was blocked at $5 \mathrm{~d}$ after CCI-ION but was maintained at its constant peak level at all later time points. The microinjection of lidocaine into the RVM had no effect on V2 or V3 hyperalgesia at the $5 \mathrm{~d}$ after CCI time point but produced robust attenuation of both primary and secondary hyperalgesia at the later $14 \mathrm{~d}$ after CCI time point that was tested. We conclude that the peripheral afferent input dominates the induction phase of primary and secondary hyperalgesia and the maintenance of primary hyperalgesia. In the transition to the later maintenance phase after CCI-ION, the RVM descending facilitatory effect appears to be sufficient to maintain secondary hyperalgesia in the absence of peripheral afferent drive but not sufficient to maintain primary hyperalgesia. We conclude that peripheral input from the injured nerve is sufficient for the induction and maintenance of primary hyperalgesia but not sufficient for the maintenance of later secondary hyperalgesia.
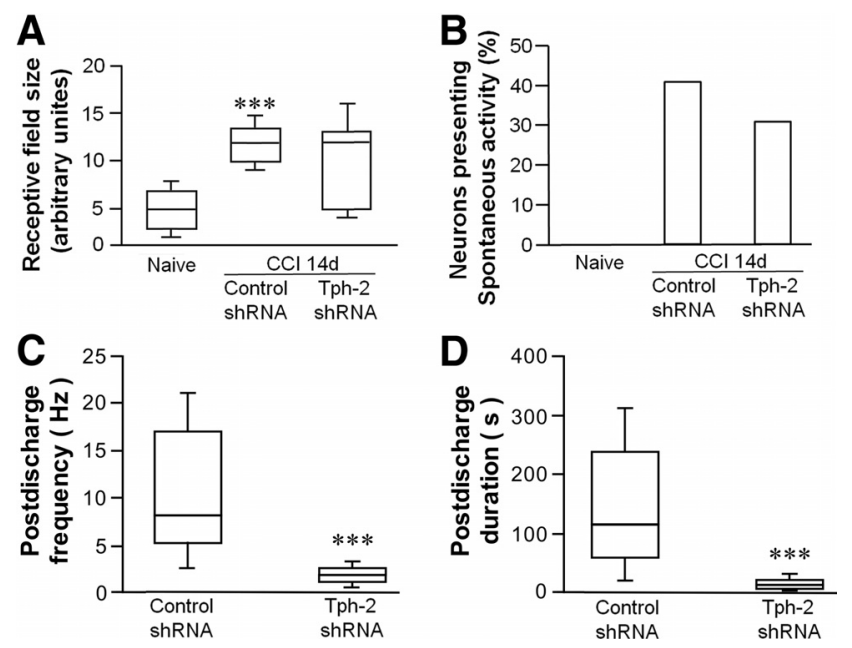

Figure 7. Effect of depletion of descending 5-HT on the maintenance of neural hyperexcitability in the $\mathrm{Vc}$ at $14 \mathrm{~d}$ after $\mathrm{CCl}-\mathrm{ION}$. Pooled data are collected from $\mathrm{Vc}$ neurons in C(I-treated rats with Tph-2 shRNA (22 neurons) and control shRNA ( $n=12)$. $A$, RF sizes of Vc WDR neurons in CCI-ION rats post-treated with control shRNA were significantly larger than RF sizes in naive rats ( $p<0.001$ vs naive). However, there was no difference in the RFs sizes between Tph-2 shRNA-treated and control shRNA-treated groups after $\mathrm{CCI}-\mathrm{ION}$. $\boldsymbol{B}$, The percentage of neurons exhibiting spontaneous activity in $\mathrm{V} c$ neurons at $14 \mathrm{~d}$ post-C(I-ION was similar in rats receiving Tph-2 shRNA (41\%) compared with rats receiving control shRNA (31\%). No Vc neurons in naive rats had spontaneous activity. $C, D$, Depletion of descending 5 -HT attenuated the postdischarge frequency $(\boldsymbol{C})$ and duration $(\boldsymbol{D})$ of neuronal poststimulus discharges. ${ }^{* *} p<0.001$, vs control shRNA.

Induction and early maintenance of primary and secondary hyperalgesia involve central sensitization mechanisms in Vc neurons that are dependent on peripheral input

Our electrophysiology experiments revealed phenotypes in Vc similar to those found in models of neuropathy after spinal nerve injury, including enlarged RFs and increased neuronal poststimulus discharge frequency and duration (Kim and Chung, 1992). These characteristics are thought to be measures of increases in dorsal horn hyperexcitability related to central sensitization (Chapman et al., 1998; Pitcher and Henry, 2000; Fossat et al., 2010). Our data indicate that the early phase (3-5 d) of primary and secondary hyperalgesia is related to Vc neuronal hyperexcitability that is peripheral input-dependent because it is totally blocked by local anesthesia. Our findings in Vc WDR neurons also demonstrate that primary afferent drive accounts for their spontaneous activity after CCI-ION because it persists after descending 5-HT depletion. Poststimulus discharge duration and frequency observed in the induction and early maintenance phase of secondary hyperalgesia were both attenuated after NB, indicating that they were both dependent, in part, on peripheral input.

\section{Maintenance of secondary hyperalgesia involves supraspinal serotonin mechanisms}

A second major finding in this study is that the late maintenance phase of secondary hyperalgesia is dependent on 5-HT input from the RVM. We have demonstrated this by the molecular depletion of Tph-2, the rate-limiting enzyme in the synthesis of neuronal 5-HT, using regional RNA interference (Wei et al., 2010). In our previous studies, Tph-2 shRNA produced prolonged downregulation of Tph-2 in the RVM and 5-HT in the spinal and medullary $(\mathrm{Vc})$ dorsal horns for up to $7 \mathrm{~d}$ (Wei et al., 2010; Chai et al., 2012). We also previously showed that 5-HTdepleted rats exhibit normal pain sensitivity but that tissue or 
nerve injury-induced hyperalgesia was markedly attenuated. In the present study, Tph-2 shRNA treatment in the RVM had no significant effect on primary and secondary hyperalgesia at $5 \mathrm{~d}$ after CCI; however, it attenuated both primary and secondary hyperalgesia at 14 and $28 \mathrm{~d}$ after CCI.

\section{The maintenance phase of secondary hyperalgesia involves central sensitization in Vc neurons that is descending 5-HT input-dependent}

In the maintenance phase (7-28 d), descending input is an important contributor to central sensitization because poststimulus discharge frequency and duration of nociresponsive neurons were significantly attenuated by RVM 5-HT depletion. Consistent with this finding was the observation that poststimulus discharge duration was not dependent on peripheral drive. In the late maintenance phase, depletion of RVM 5-HT input had no effect on RF size and spontaneous activity of $\mathrm{Vc}$ neurons. This is consistent with conclusions from the NB experiments that these effects of central sensitization were dependent on peripheral input. In addition, poststimulus discharge frequency was also significantly reduced by peripheral NB. It appears that both descending and peripheral inputs are contributing to the maintenance of neuronal hyperexcitability in the late phase of secondary hyperalgesia.

Previous findings support a role for plateau potentials as an intrinsic property present in deep dorsal horn neurons, which can account for the poststimulus discharges (Morisset and Nagy, 2000; Fossat et al., 2010). Plateau potentials are also strongly modulated by $5-\mathrm{HT}$ and are an intrinsic mechanism for amplification of electrophysiological signals (Hounsgaard and Kiehn, 1989; Russo and Hounsgaard, 1996; Perrier and Hounsgaard, 2003). The modulation of plateau potentials and their maintenance by descending 5-HT open the possibility of new treatments aimed at attenuating the maintenance of persistent pain.

5-HT axons terminating in the Vc originate mainly in the RVM and activate a number of heterogeneous receptors in the dorsal horn (Millan, 2002; Wei et al., 2010). An excitatory response is mediated mainly through the ionotropic $5-\mathrm{HT}_{3}$ receptor (Suzuki et al., 2002; Wei et al., 2010). Therefore, we tested the effects of microinjection of a selective $5-\mathrm{HT}_{3}$ receptor antagonist into the $\mathrm{Vc}$ on primary and secondary hyperalgesia at early and late time points. Consistent with our findings after RVM 5-HT depletion, functional blockade of 5-HT receptor activation had a minor effect on both primary and secondary hyperalgesia at $5 \mathrm{~d}$ after CCI, whereas at $14 \mathrm{~d}$ after CCI it attenuated both primary and secondary hyperalgesia, suggesting that $5-\mathrm{HT}_{3}$ receptor activation contributes to the central sensitization in $\mathrm{Vc}$ neurons and the maintenance of the late-phase secondary hyperalgesia. By combining the effects of peripheral NB of ION followed by administration of a $5-\mathrm{HT}_{3}$ receptor antagonist into the $\mathrm{Vc}$, we determined that the ION NB had a small effect on the secondary hyperalgesia from $\mathrm{V} 3$, whereas the subsequent microinjection of a 5-HT3 receptor antagonist significantly attenuated the secondary hyperalgesia, confirming that descending 5-HT facilitatory input may be a more dominant contributor to the secondary hyperalgesia in the late maintenance phase. The switch to descending input-dependent central sensitization in $V_{c}$ in the maintenance of secondary hyperalgesia provides a mechanism that may account for the transition from acute to chronic pain in conditions where hyperalgesia spreads beyond the site innervated by the injured nerve.

Secondary hyperalgesia involving RVM circuitry is important because the spread of hyperalgesia to nearby noninjured territo- ries (Fernández-de-las-Peñas et al., 2009) can serve a protective function similar to acute pain. The RVM receives major input from the periaqueductal gray, which receives converging input from forebrain sites, such as the prefrontal cortex, insular cortex, anterior cingulate cortex, and the amygdala, which play important roles in the emotional and cognitive components of the pain experience (Apkarian et al., 2005; Tracey and Bushnell, 2009). These descending inputs can provide modulation, including facilitatory effects on central sensitization underlying the longterm maintenance of hyperalgesia after nerve or tissue injury.

Our findings suggest novel approaches to the treatment of persistent pain conditions in which the pain has spread beyond the site of injury, and secondary hyperalgesia plays an important role. It may be important to relieve the pain at an early stage when the hyperalgesia is primarily peripheral input-dependent. When the pain becomes central input-dependent, treatments at the site of injury may be insufficient to attenuate the hyperalgesia and agents that modify central sensitization may be necessary.

5-HT modulates trigeminal and spinal dorsal horn neuronal activity in a complex manner because of the involvement of multiple 5-HT receptor subtypes and their localization. Selective serotonin reuptake inhibitors have not been successful in the treatment of neuropathic pain in humans (Finnerup et al., 2010), partly because of the multiple 5-HT receptor subtypes that produce both inhibition and facilitation in the spinal and medullary dorsal horn (Fonseca et al., 2001; Millan, 2002; Lopez-Garcia, 2006). Clinical studies have examined the effects of $5-\mathrm{HT}_{3}$ receptor antagonists in the treatment of neuropathic pain and fibromyalgia with minimal success (McCleane et al., 2003; Seidel and Müller, 2011; Förster and Baron, 2012; Neziri et al., 2012). More knowledge about plasticity in the expression of these receptor subtypes after nerve injury as well as the use of combinations of agents that enhance 5-HT inhibition and suppress excitation may be necessary to achieve successful treatment interventions involving the 5-HT system at the dorsal horn level.

\section{References}

Apkarian AV, Bushnell MC, Treede RD, Zubieta JK (2005) Human brain mechanisms of pain perception and regulation in health and disease. Eur J Pain 9:463-484. CrossRef Medline

Basbaum AI, Bautista DM, Scherrer G, Julius D (2009) Cellular and molecular mechanisms of pain. Cell 139:267-284. CrossRef Medline

Berde CB, Athiraman U, Yahalom B, Zurakowski D, Corfas G, Bognet C (2011) Tetrodotoxin-bupivacaine-epinephrine combinations for prolonged local anesthesia. Mar Drugs 9:2717-2728. CrossRef Medline

Burgess SE, Gardell LR, Ossipov MH, Malan TP Jr, Vanderah TW, Lai J, Porreca F (2002) Time-dependent descending facilitation from the rostral ventromedial medulla maintains, but does not initiate, neuropathic pain. J Neurosci 22:5129-5136. Medline

Chai B, Guo W, Wei F, Dubner R, Ren K (2012) Unilateral-induced contralateral orofacial hyperalgesia requires descending activation of $5-\mathrm{HT}_{3}$ receptors in the contralateral ViVc. Mol Pain 8:78. CrossRef Medline

Chapman V, Suzuki R, Dickenson AH (1998) Electrophysiological characterization of spinal neuronal response properties in anaesthetized rats after ligation of spinal nerves L5-L6. J Physiol 507:881-894. CrossRef Medline

Chen Y, Devor M (1998) Ectopic mechanosensitivity in injured sensory axons arises from the site of spontaneous electrogenesis. Eur J Pain 2:165178. CrossRef Medline

Derjean D, Bertrand S, Le Masson G, Landry M, Morisset V, Nagy F (2003) Dynamic balance of metabotropic inputs causes dorsal horn neurons to switch functional states. Nat Neurosci 6:274-281. CrossRef Medline

Devor, M (2009) Ectopic generators. In: Science of pain (Basbaum AI, Bushnell MC, eds), pp 83-88. Oxford, United Kingdom: Academic.

Durham PL, Garrett FG (2010) Emerging importance of neuron-satellite glia interactions within trigeminal ganglia in craniofacial pain. Open Pain J 3:3-13. CrossRef 
Fernández-de-las-Peñas C, Galán-del-Río F, Fernández-Carnero J, Pesquera J, Arendt-Nielsen L, Svensson P (2009) Bilateral widespread mechanical pain sensitivity in women with myofascial temporomandibular disorder: evidence of impairment in central nociceptive processing. J Pain 10: 1170-1178. CrossRef Medline

Finnerup NB, Sindrup SH, Jensen TS (2010) The evidence for pharmacological treatment of neuropathic pain. Pain 150:573-581. CrossRef Medline

Fonseca MI, Ni YG, Dunning DD, Miledi R (2001) Distribution of serotonin $2 \mathrm{~A}, 2 \mathrm{C}$ and 3 receptor mRNA in spinal cord and medulla oblongata. Brain Res Mol Brain Res 89:11-19. CrossRef Medline

Förster M, Baron R (2012) One failed clinical trial (of 5HT3 antagonists) does not invalidate the concept. Pain 153:263-264. CrossRef Medline

Fossat P, Sibon I, Le Masson G, Landry M, Nagy F (2007) L-type calcium channels and NMDA receptors: a determinant duo for short-term nociceptive plasticity. Eur J Neurosci 25:127-135. CrossRef Medline

Fossat P, Dobremez E, Bouali-Benazzouz R, Favereaux A, Bertrand SS, Kilk K, Léger C, Cazalets JR, Langel U, Landry M, Nagy F (2010) Knockdown of L calcium channel subtypes: differential effects in neuropathic pain. J Neurosci 30:1073-1085. CrossRef Medline

Green GM, Scarth J, Dickenson A (2000) An excitatory role for 5-HT in spinal inflammatory nociceptive transmission: state-dependent actions via dorsal horn 5-HT3 receptors in the anaesthetized rat. Pain 89:81-88. CrossRef Medline

Hounsgaard J, Kiehn O (1989) Serotonin-induced bistability of turtle motoneurones caused by a nifedipine-sensitive calcium plateau potential. J Physiol 414:265-282. Medline

Jones LM, Depireux DA, Simons DJ, Keller A (2004a) Robust temporal coding in the trigeminal system. Science 304:1986-1989. CrossRef Medline

Jones LM, Lee S, Trageser JC, Simons DJ, Keller A (2004b) Precise temporal responses in whisker trigeminal neurons. J Neurophysiol 92:665-668. CrossRef Medline

Kim SH, Chung JM (1992) An experimental model for peripheral neuropathy produced by segmental spinal nerve ligation in the rat. Pain 50:355363. CrossRef Medline

Lagraize SC, Guo W, Yang K, Wei F, Ren K, Dubner R (2010) Spinal cord mechanisms mediating behavioral hyperalgesia induced by neurokinin-1 tachykinin receptor activation in the rostral ventromedial medulla. Neuroscience 171:1341-1356. CrossRef Medline

Lopez-Garcia JA (2006) Serotonergic modulation of spinal sensory circuits. Curr Top Med Chem 6:1987-1996. CrossRef Medline

Martin YB, Malmierca E, Avendaño C, Nuñez A (2010) Neuronal disinhibition in the trigeminal nucleus caudalis in a model of chronic neuropathic pain. Eur J Neurosci 32:399-408. CrossRef Medline

McCleane GJ, Suzuki R, Dickenson AH (2003) Does a single intravenous injection of the 5HT3 receptor antagonist ondansetron have an analgesic effect in neuropathic pain? A double-blinded, placebo-controlled crossover study. Anesth Analg 97:1474-1478. CrossRef Medline

Millan MJ (2002) Descending control of pain. Prog Neurobiol 66:355-474. CrossRef Medline

Morisset V, Nagy F (1998) Nociceptive integration in the rat spinal cord: role of non-linear membrane properties of deep dorsal horn neurons. Eur J Neurosci 10:3642-3652. CrossRef Medline

Morisset V, Nagy F (2000) Plateau potential-dependent windup of the response to primary afferent stimuli in rat dorsal horn neurons. Eur J Neurosci 12:3087-3095. CrossRef Medline

Neziri AY, Dickenmann M, Scaramozzino P, Andersen OK, Arendt-Nielsen L, Dickenson AH, Curatolo M (2012) Effect of intravenous tropisetron on modulation of pain and central hypersensitivity in chronic low back pain patients. Pain 153:311-318. CrossRef Medline

Perrier JF, Hounsgaard J (2003) 5-HT2 receptors promote plateau potentials in turtle spinal motoneurons by facilitating an L-type calcium current. J Neurophysiol 89:954-959. Medline

Pitcher GM, Henry JL (2000) Cellular mechanisms of hyperalgesia and spontaneous pain in a spinalized rat model of peripheral neuropathy: changes in myelinated afferent inputs implicated. Eur J Neurosci 12: 2006-2020. CrossRef Medline

Porreca F, Ossipov MH, Gebhart GF (2002) Chronic pain and medullary descending facilitation. Trends Neurosci 25:319-325. CrossRef Medline

Ren K, Dubner R (2008) Descending control mechanisms. In: The senses: a comprehensive reference (Basbaum AI, Kaneko A, Shepherd GM, Wes- theimer G, eds), Vol 5: Pain (Bushnell MC, Basbaum AI, eds), pp 723762. San Diego: Academic.

Ringkamp M, Meyer RA (2005) Injured versus uninjured afferents: who is to blame for neuropathic pain? Anesthesiology 103:221-223. CrossRef Medline

Russo RE, Hounsgaard J (1996) Plateau-generating neurones in the dorsal horn in an in vitro preparation of the turtle spinal cord. J Physiol 493:3954. Medline

Rygh LJ, Svendsen F, Hole K, Tjølsen A (1999) Natural noxious stimulation can induce long-term increase of spinal nociceptive responses. Pain 82: 305-310. CrossRef Medline

Seidel MF, Müller W (2011) Differential pharmacotherapy for subgroups of fibromyalgia patients with specific consideration of 5-HT3 receptor antagonists. Expert Opin Pharmacother 12:1381-1391. CrossRef Medline

Shapiro SS, Wilk MB (1965) An analysis of variance test for normality (complete samples). Biometrika 52:591-611. CrossRef

Shibuta K, Suzuki I, Shinoda M, Tsuboi Y, Honda K, Shimizu N, Sessle BJ, Iwata K (2012) Organization of hyperactive microglial cells in trigeminal spinal subnucleus caudalis and upper cervical spinal cord associated with orofacial neuropathic pain. Brain Res 1451:74-86. CrossRef Medline

Shim B, Ringkamp M, Lambrinos GL, Hartke TV, Griffin JW, Meyer RA (2007) Activity-dependent slowing of conduction velocity in uninjured L4 C fibers increases after an L5 spinal nerve injury in the rat. Pain 128: 40-51. CrossRef Medline

Staud R, Robinson ME, Weyl EE, Price DD (2010) Pain variability in fibromyalgia is related to activity and rest: role of peripheral tissue impulse input. J Pain 11:1376-1383. CrossRef Medline

Sun Q, Tu H, Xing GG, Han JS, Wan Y (2005) Ectopic discharges from injured nerve fibers are highly correlated with tactile allodynia only in early, but not late, stage in rats with spinal nerve ligation. Exp Neurol 191:128-136. CrossRef Medline

Suzuki R, Morcuende S, Webber M, Hunt SP, Dickenson AH (2002) Superficial NK1-expressing neurons control spinal excitability through activation of descending pathways. Nat Neurosci 5:1319-1326. CrossRef Medline

Svendsen F, Rygh LJ, Gjerstad J, Fiskå A, Hole K, Tjølsen A (1999) Recording of long-term potentiation in single dorsal horn neurons in vivo in the rat. Brain Res Brain Res Protoc 4:165-172. CrossRef Medline

Tal M, Bennett GJ (1994) Extra-territorial pain in rats with a peripheral mononeuropathy: mechano-hyperalgesia and mechano-allodynia in the territory of an uninjured nerve. Pain 57:375-382. CrossRef Medline

Tracey I, Bushnell MC (2009) How neuroimaging studies have challenged us to rethink: is chronic pain a disease? J Pain 10:1113-1120. CrossRef Medline

Tsuboi Y, Takeda M, Tanimoto T, Ikeda M, Matsumoto S, Kitagawa J, Teramoto K, Simizu K, Yamazaki Y, Shima A, Ren K, Iwata K (2004) Alteration of the second branch of the trigeminal nerve activity following inferior alveolar nerve transection in rats. Pain 111:323-334. CrossRef Medline

Urch CE, Dickenson AH (2003) In vivo single unit extracellular recordings from spinal cord neurones of rats. Brain Res Brain Res Protoc 12:26-34. CrossRef Medline

Viggiano A, Monda M, Viggiano A, Viggiano D, Viggiano E, Chiefari M, Aurilio C, De Luca B (2005) Trigeminal pain transmission requires reactive oxygen species production. Brain Res 1050:72-78. CrossRef Medline

Wall PD, Gutnick M (1974) Ongoing activity in peripheral nerves: the physiology and pharmacology of impulses originating from a neuroma. Exp Neurol 43:580-593. CrossRef Medline

Wei F, Guo W, Zou S, Ren K, Dubner R (2008) Supraspinal glial-neuronal interactions contribute to descending pain facilitation. J Neurosci 28 : 10482-10495. CrossRef Medline

Wei F, Dubner R, Zou S, Ren K, Bai G, Wei D, Guo W (2010) Molecular depletion of descending serotonin unmasks its novel facilitatory role in the development of persistent pain. J Neurosci 30:8624-8236. CrossRef Medline

Woolf CJ (2011) Central sensitization: implications for the diagnosis and treatment of pain. Pain 152 [Suppl 3]:S2-S15.

Zeitz KP, Guy N, Malmberg AB, Dirajlal S, Martin WJ, Sun L, Bonhaus DW, Stucky CL, Julius D, Basbaum AI (2002) The 5-HT3 subtype of serotonin receptor contributes to nociceptive processing via a novel subset of 
myelinated and unmyelinated nociceptors. J Neurosci 22:1010-1019. Medline 